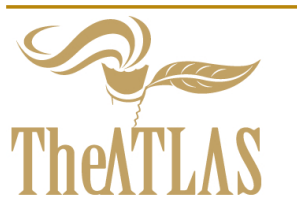

\title{
Designing Transdisciplinary Discovery and Innovation: Models and Tools for Dynamic Knowledge Integration
}

Derrick Tate, Texas Tech University Department of Mechanical Engineering, Lubbock, Texas, USA, Email: d.tate@ttu.edu

doi: $10.22545 / 2010 / 0004$

his paper presents challenges faced in rapidly accelerating technological development and the need for a transdisciplinary approach to engineering systems. An analogy is drawn with theories of technical system development to propose a mechanism for dynamic knowledge integration using transdisciplinary approaches. The mechanism for $d y$ namic knowledge integration is based on a three-level progression of the scope of transdisciplinary research activities. Concepts and tools from engineering design and innovation are used to explain challenges and opportunities for the future of transdisciplinary research, and preliminary measures for transdisciplinary and interdisciplinary knowledge integration are discussed. Validation of transdisciplinary research is then discussed in light of approaches to philosophy of science and the sociology of intellectual dis-course. Examples are given of transdisciplinary research areas that combine engineering design with other fields such as sustainability, biology, management of technology.

Keywords: transdisciplinary research, engineering innovation, knowledge integration, technological system development.

\section{Introduction}

In this paper, the author argues for the need of a transdisciplinary research and educational framework to address large-scale, modern engineering systems and to prepare engineers, designers, and researchers of the future. In discussing this need, the author considers several issues: the theoretical issues involved in crossing disciplinary boundaries, the development of more comprehensive understandings of large-scale problems, and the integration of concepts and methods from multiple disciplines.

During the last decade, the number of complex problems facing society has exploded, and the technical knowledge and understanding in science and engineering required to address these problems is rapidly evolving. The National Academy of Engineering (NAE) has presented a list of the twenty greatest engineering achievements of the Twentieth Century. These engineering contributions celebrate technical achievement and highlight the impact of engineering on the quality of life [1]. All of them have created complex engineering systems and result from the contributions of multiple disciplines. A few examples of the rapid pace of technological changes are the groundbreaking advancements in semicon- 
ductor and software technologies, the biosciences, nanotechnology, and cognitive sciences [2].

In addition to the great achievements of engineering, the list of failures is growing as well. Recent failures include delayed schedules and cost overruns, projects that go back to the drawing board halfway through the development process, and those that never get implemented at all [3-5]. Often these failures arise at the interface between the engineering systems and their social-technical interfaces. Many trends pose challenges-or opportunities-for the future: globalization; energy demands; environmental impacts; social, cultural, political, and economic forces; new human-machine interactions; new, open ways of distributing knowledge; and a more pervasive presence of technology throughout society [6-8].

The world has changed due to globalization, including multinational $\mathrm{R} \& \mathrm{D}$ facilities in developing countries, high-tech production in China, and the outsourcing of service jobs to India. Yet, engineering education-especially at the undergraduate level in the US - has remained substantially unchanged since the 1950s when the current structure of engineering education was established to meet cold-war concerns about science as codified in the Grinter report of 1955, [9-11].

As Nobel Laureate Herbert Simon stated, "We have learned very well that many of the systems that we are trying to deal with in our contemporary science and engineering are very complex indeed. They are so complex that it is not obvious that the powerful tricks and procedures that served us for four centuries or more in the development of modern science and engineering will enable us to understand and deal with them. We are learning that we need a science of complex systems..."[12]. The last two decades of designing large-scale engineering systems has taught us that neither mono-, multi-, or inter-disciplinary approaches provide the environment that is necessary to promote the level of synthesis and collaboration that is necessary to extend beyond existing disciplinary boundaries and produce truly creative and innovative solutions to large-scale, complex problems.

This paper aims to clarify some of theoretical issues involved in crossing disciplinary boundaries from an engineering perspective, contribute to a more holistic understanding of large-scale problems, and describe from a technological standpoint, the integration of concepts and methods from multiple disciplines. This paper is structured as follows:

Section 1 introduces the challenges faced because of rapidly accelerating technological development and motivates the need for a transdisciplinary approach to engineering systems. Section 2 defines transdisciplinary research, shows the importance of engineering and design, and discusses open and mass innovation concepts. Section 3 draws on an analogy with theories of technical system development to propose a mechanism for dynamic knowledge integration using transdisciplinary approaches.

The mechanism for dynamic knowledge integration is based on a three-level progression of the scope of transdisciplinary research activities. The author draws parallels between transdisciplinary research efforts and analogous activities in engineering innovation. Concepts and tools from engineering innovation are used to explain challenges and opportunities for the future of transdisciplinary research, and preliminary measures for transdisciplinary and interdisciplinary knowledge integration are discussed. Validation of transdisciplinary research is then discussed in light of approaches to philosophy of science and the sociology of intellectual discourse.

Section 4 describes examples of transdisciplinary research that combine engineering design with other fields such as sustainability, biology, and management of technology (management and economics). Section 5 discusses challenges in creating a transdisciplinary science for engineering. Section 6 presents a summary and conclusions.

\section{Need for Transdisciplinary Approaches}

Although there may be much buzz these days about interdisciplinary and multidisciplinary research, efforts at cooperation between disciplines are often ad hoc, driven by the desire to secure funding for a particular project [13]. Is there an underlying connection between the disciplines, and if so, what is it?

\subsection{Characteristics of Transdisciplinary Approaches}

Kollman and Ertas provide a summary of definitions of transdisciplinary approaches and distinguish transdisciplinary efforts from other cross-disciplinary 
approaches such as multidisciplinary and interdisciplinary efforts. They present the results of a survey that show that transdisciplinary efforts are characterized by sustained collaboration and a high quality of integration among methods and approaches [14].

Efforts to define and establish transdisciplinary research can be traced back to the early 1970s [15, 16]. According to the Oxford English Dictionary, the term transdisciplinary appeared in 1972 and may be defined as "Of or pertaining to more than one discipline or branch of learning." From its earliest usage, transdisciplinary indicates greater cooperation and integration between disciplines than do interdisciplinary or multidisciplinary [17]:

1972 E. JANTSCH in OECD: Interdisciplinarity II. i. 105 The ultimate degree of co-ordination in the education/innovation system,... which may be called transdisciplinarity, would...depend on a common anxiomatics [sic]....The whole education..system would be coordinated as a multi-level, multi-goal system, embracing a multitude of...interdiscipli-nary two-level systems, which... will be modified in the transdisciplinary framework.

Transdisciplinary education and research take collaboration across discipline boundaries a step further than do multidisciplinary and interdisciplinary programs. Transdisciplinary goes beyond multidisciplinary and interdisciplinary to mutually share methods and subjects between disciplines [18]. Nicolescu describes the three-fold nature of transdisciplinarity: "Transdisciplinarity concerns that which is at once between the disciplines, across the different disciplines, and beyond all disciplines." He continues by stating that its "goal is the understanding of the present world, of which one of the imperatives is the unity of knowledge," [15].

Multidisciplinary research is characterized by studying a research topic from the perspective of multiple disciplines at the same time. Specifically, a multidisciplinary approach uses methods from two or more disciplines to examine a common topic. According to Kollman and Ertas, "Multidisciplinary teams do cross discipline boundaries; however, they remain limited to the framework of disciplinary research," [14]. In general, researchers from different disciplines work independently, each from his or her own discipline-specific perspective to address a common topic.

Interdisciplinary research involves the application of a method from one discipline to topics studied by other disciplines. According to Kollman and Ertas, "In...interdisciplinary activities, researchers from different disciplines work jointly on common problems by exchanging methods, tools, and concepts...to find integrated solutions," [14]. In other words, interdisciplinary research concerns the transfer of techniques methodsbetween disciplines.

Most recently, Ertas lists several characteristics of transdisciplinary research. Namely, it "us[es]... shared concepts, frameworks, tools, methodologies and technologies to solve common unstructured research problems; eliminates disciplinary boundaries for strong collaboration; redefines the boundaries of natural science, social science, humanities and engineering by bridging them, and leads [to] the development of new knowledge, shared common conceptual frameworks, tools, methodologies and technologies," [19]. Engineering must play a vital role in advancing transdisciplinary efforts, and conversely transdisciplinary efforts will further advance engineering, technology, and science.

\subsection{Importance of Engineering and Design}

Having a fundamental understanding of engineering systems has become increasingly important as the pace of technological development has accelerated due to global collaboration and competition. Technology has driven changes in design and development processes for engineering systems [20]. Products have become integrated engineering systems, and design and production requirements cross disciplinary boundaries. Knowledge from many disciplines - within engineering as well as other disciplines outside of science and engineering, such as business, social sciences, medicine, etc. - needs to be integrated to create effective systems or products.

According to Ertas, the essence of the transdisciplinary approach is "a foundation of design fundamentals and process development and management....This core is then surrounded by knowledge and skill 'tools' selected from various disciplines. These tools can be updated as needed to keep pace with developing technology," [20]. The process envisioned for achieving transdisciplinary engineering starts with "extract[ing] the common elements, design and process, from existing disciplines and syn- 
thesiz[ing] them into the foundation of the new transdiscipline...The transdisciplinary approach provides an umbrella of the core design, process, systems, and metrics common to all disciplines that [are] necessary for problem solving," [21].

Science alone will not be able to solve today's problems. Petroski has noted the importance of engineering and its neglect by society in comparison with science. In particular, Petroski believes that the creativity and initiative that mark engineering efforts are vital to addressing national and global challenges [22].

Public perception of engineering recognizes its importance to national and international competitiveness, economy, quality of life, security, but uncertainty about engineering among the general public remains. Conflicting perspectives on the essential attributes that comprise the engineering design process result in a lack of coherent criteria for introducing engineering to P-12 students and an inability to make engineering an attractive discipline for prospective students and to improve public perceptions of the contributions of engineering [23].

A recent study by the NAE highlights the challenges: The strongest association with the engineering profession that was identified by the general public and prospective students is the need for strong science and math skills among engineering practitioners. The authors of the report conclude that the commonly used approach of engineering outreach, namely emphasizing science and math and the practical benefits of being an engineer "may damage rather than increase the appeal of engineering." It overemphasizes their importance instead of placing these subjects "correctly, as just two of a number of skills and dispositions...necessary to [be] a successful engineer." The report instead recommends emphasizing "the inspirational, optimistic aspects of engineering" similar to the image of a "physician... who cures diseases and relieves human suffering." As they note, "The medical profession does not market itself to young people by pointing out that they will have to study organic chemistry or by emphasizing the long, hard road to becoming a physician," [24].

The difference between science and engineering can be captured in the statement by von Karman: "Scientists study the world as it is, engineers create the world that never has been." Sohlenius expands on this thought by explaining that an engineer "analyses what is, imagines what should be, creates what has never been, analyses the results of the creation," [25]. Simon contrasts the subjects of inquiry in science and engineering as "natural things: how they are and how they work" in contrast to "artificial things: how to make artifacts that have desired properties and how to design," [26].

To explain the overemphasis on science in engineering education requires a historical analysis of the forces that shaped engineering curricula after World War II. [27] According to Simon, "Schools of engineering... are all centrally concerned with the process of design.... [yet] it is ironic that in [the twentieth] century the natural sciences almost drove the sciences of the artificial from professional school curricula, a development that peaked about two or three decades after the Second World War. Engineering schools gradually became schools of physics and mathematics....The use of adjectives like applied concealed, but did not change, the fact," [26]. In particular, there was a shift towards "engineering science" subjects at the expense of design and manufacturing, even to the point that "the education system has treated engineering as synonymous with engineering science," [28]. "The idea that engineering is an 'applied science' had affected many programs adversely....[I]t sent the wrong message to engineering schools and reinforced the idea that the reductionism model of engineering research is what engineering research was all about. It downgraded technology innovation, design, manufacturing, and other related fields," [29].

While the shift to "engineering science" may have made sense in the context of the cold war [27], a re-emphasis on the creative aspects of engineering design is needed to maintain competitiveness in the current globalizing context.

\subsection{Open and Mass Innovation Approaches}

Innovation is a broader activity than invention - including not only the physical realization of a novel idea, but also including its acceptance. "The leaning towards cross-disciplinarity that characterizes much scholarly work in this area reflects the fact that no single discipline deals with all aspects of innovation. Hence, to get a comprehensive view, it is necessary to combine insights from several disciplines." [30] The Oxford Handbook of Innovation provides a summary of the contribution of various fields to understanding innovation processes - yet does not include engineer- 
Table 1: TRIZ Level of Invention [35-37].

\begin{tabular}{|c|c|c|}
\hline Level & Description & \% of Patents [36] \\
\hline Level 1 & $\begin{array}{c}\text { Apparent solution: A component intended for a task is used. No } \\
\text { system conflicts are resolved. }\end{array}$ & $32 \%$ \\
\hline Level 2 & $\begin{array}{c}\text { Small improvement: An existing system is slightly modified. System } \\
\text { conflict(s) are resolved through transfer of a solution from a } \\
\text { similar technical system. }\end{array}$ & $45 \%$ \\
\hline Level 3 & $\begin{array}{c}\text { Invention inside paradigm: At least one system component is } \\
\text { radically changed or eliminated to resolve system conflict(s); } \\
\text { the problem and solution are within one discipline. }\end{array}$ & $19 \%$ \\
\hline Level 4 & $\begin{array}{l}\text { Invention outside paradigm: A new system is developed that } \\
\text { resolves system conflict(s) using a solution that is } \\
\text { interdisciplinary. }\end{array}$ & $<4 \%$ \\
\hline Level 5 & $\begin{array}{c}\text { Discovery: A pioneering invention is created, often based on } \\
\text { recently discovered phenomenon. }\end{array}$ & $<0.3 \%$ \\
\hline
\end{tabular}

ing. It lists economics, cognitive science, sociology, organizational science, management, economic geography, economic history, and history of technology [30].

An example of an innovation model from the discipline of management is the concept of open innovation $[31,32]$. This view is based on the premise that useful knowledge is widely distributed, not only found within a firm. All companies need to seek out, connect with, and leverage these intra-firm and external sources of innovation. Moreover, the resulting products and systems can go to market from within or outside the firm as well. Open innovation research can be categorized according to its focus on the individual, organization, value network, or industry sector. It studies inflow and outflow of ideas and products and accompanying policies and enabling practices. According to Chesbrough et al., "The open innovation paradigm treats $\mathrm{R} \& \mathrm{D}$ as an open system. Open innovation suggests that valuable ideas can come from within or outside the company and can go to market from within or outside the company as well.... Open innovation assumes that useful knowledge is widely distributed, and that even the most capable $R \& D$ organizations must identify, connect to, and leverage external knowledge sources as a core process in innovation," [31].

Globalization and cyberinfrastructure provide new mechanisms to create opportunities for mass innovation, which the author defines as "expanding and diffusing innovation activities to the general population through connecting individual inventors and entrepreneurs with the engineering tools and services needed to assess and realize their novel design concepts," [33].

In contrast to the firm-level approach of management science, an approach for evaluating innovation that is based on the technical content of a patented idea is the concept of level of invention. This was defined by Altshuller as a part of the theory of inventive problem solving (TRIZ) [34]. The five levels of invention are based on the resolution of system conflicts (caused by functional coupling) through transdisciplinary approaches. These levels of invention are based on the combination of the resolution of system conflicts and the borrowing of solutions from within or outside the discipline of the conflict. [35-37]. Table 1 shows criteria for the five levels of inventions and their definitions.

It is notable that the definitions of these levels of invention take into account knowledge transfer and integration. Note that the higher levels of invention that are the goal of engineering design research and industrial practice include by definition a greater degree of knowledge transfer from one discipline to another; that is, knowledge for the higher levels of invention come from disciplines that are more intellectually distant from the problem being solved.

\section{Model of Transdisciplinary Knowledge Integration}

In this section a model of transdisciplinary research is presented. The purpose of this model is sketch a research process that can be applied in transdisciplinary research. The input of the process is a research question, and the output is a set of concepts, 
Table 2: Activities in Transdisciplinary Research Compared with Innovation Processes.

\begin{tabular}{|l|l|}
\hline \multicolumn{1}{|c|}{ Transdisciplinary Research E } & \multicolumn{1}{c|}{ ngineering Innovation } \\
\hline Identification of need I & dentification of need \\
\hline $\begin{array}{c}\text { Assessment of need, value and definition of } \\
\text { scope }\end{array}$ & $\begin{array}{c}\text { Assessment of innovative potential, financial } \\
\text { analysis, and definition of project scope }\end{array}$ \\
\hline Team formation and collaboration & $\begin{array}{c}\text { Project control and collaboration OR } \\
\text { Open innovation }\end{array}$ \\
\hline Understanding models, methods, and theories & Functional modeling \\
\hline Search for models, methods, and theories & Search for technologies \\
\hline Selecting models, methods, and theories & Selection of technologies \\
\hline Integration and creation of a research program I & ntegration and Implementation \\
\hline Testing and validation T & esting and validation \\
\hline
\end{tabular}

theories, and methods that can be tested or used for explanation and prediction. The main phases of the research process are data gathering, theory development, and theory validation. Each phase comprises one or more activities that are performed to generate, transfer, or assess knowledge. In some research projects, a research team works through all phases. In other projects, one research team initiates the work, and the results of this phase are passed to others who continue the research by working in subsequent phases $[38,39]$.

\subsection{Parallels between Transdisciplinary Research and Engineering Innovation Activities}

Research into engineering design has yielded insights into the nature and structure of the design process and formal, discipline-independent representations of design objects or artifacts - the product of the design process [40-42]. Additionally design research has produced many tools to aid design activities from either a discipline-independent or an intra-disciplinary perspective. While lacking a common terminology, many of the design theories have highlighted similar insights [43]: structures for modeling, processes, "design thinking," and tools. Each of these areas sheds some insight into creativity, innovation, and knowledge transfer.

Table 2 lists parallels between transdisciplinary research and engineering design, development, and innovation activities. The purpose of discussing concepts from engineering design and drawing an analogy between transdisciplinary research and engineering designs are two-fold: first, to clarify the role of transdisciplinarity in engineering design, and second, to explain the role of engineering tools and models in understanding and aiding transdisciplinarity.

As can be seen from the table of activities, there is a great deal of commonality between transdisciplinary research and engineering innovation processes. It is the belief of the author that models, theories, and methods from engineering design will be helpful in promoting and facilitating transdisciplinary research. Likewise transdisciplinary research can broaden the perspective of engineers and promote the creation of more creative solutions than would be generated by traditional methods within individual engineering disciplines.

\subsubsection{Models of Engineering Design Processes}

Ross defines a model as " $\mathrm{M}$ is a model of $\mathrm{A}$ if $\mathrm{M}$ can be used to answer questions about A"[44]. This paper presents ideas for a model of transdisciplinary research activities for the use of either those interested in implementing transdisciplinary research processes or for those interested in explaining the events and outcomes of these processes. Common models of engineering design processes represent design activities in terms of functional modeling - identifying functional requirements and constraints that need to be satisfied for a given set of customer needs, mapping between various design spaces, such as functional and physical descriptions of the design, and hierarchical decompositions. Two tools that are useful in developing engineering systems are strategies for identifying and resolving engineering contradictions and methods for creating modular systems. Parallels 


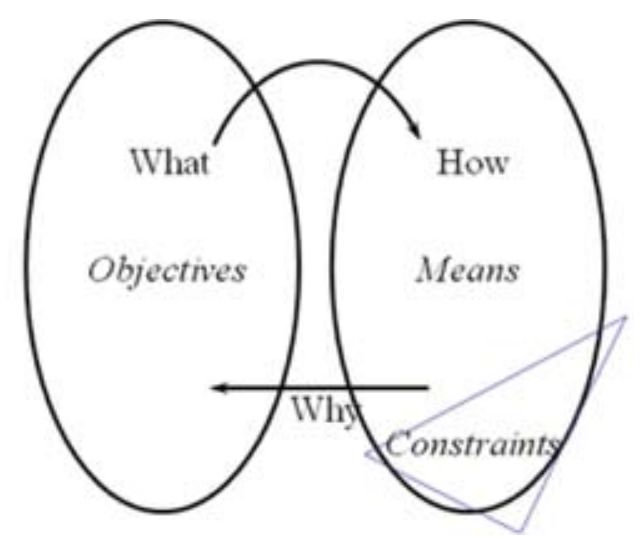

Figure 1: Domains.

between these concepts and their use in transdisciplinary research will be explored.

\section{Functional Modeling}

Formal methods used for representing functions during problem formulation describe a system's functions and how they interact $[45,46]$. They are intended to facilitate communication among designers and stakeholders, build group consensus, and support the development of innovative and collaborative designs [47]. Problem formulation has been observed to be the most difficult task in design [28], and it is critical because design programs and designed artifacts will fail if problem formulation never stabilizes or is based upon incorrect premises. Recent research in engineering design has started with a "functional basis" for representing engineering designs, yet this is only one of many approaches to modeling functions that have been proposed $[45,46]$.

The approaches to representing functions can be divided into two categories: (1) "functional basis" or "black box" approaches that trace various flows through a system (typical examples include functional basis [34, 48-50], black box, and structured analysis and design technique (SADT) [44, 51-53]) and (2) those that alternate between functions and physical means, progressing from systems to components to create a hierarchy of functions (for example, function means tree (FMT) [40, 41, 54-56] (compare with [57] and [28, 58]), enhanced FMT [59], Geros function - behavior - structure (FBS) ontology [6063], and SysML [64, 65]). Recent publications by Erdena et al. and van Eck et al. have compared and contrasted prominent approaches to functional modeling $[66,67]$.

Functional modeling can be helpful in clarifying the goals of a transdisciplinary research effort. In particular, functions can be stated using "solutionneutral language" [28] as desired transformations from an input state to an output state, independent of specific solutions. Additionally, functional basis methods can be used to map flows through relevant systems and are intended to provide a common language that can improve communication among team members [49].

\section{Mapping}

The design process can be defined as developing or selecting means to satisfy objectives, while being subject to constraints [68]. During the design process, the task that is being addressed can be divided into domains as shown in Figure 1. The nature of the design elements in each domain changes depending on the field of the problem. The domains consider the perspectives of the customer, functions, system, manufacturing process, etc. Design consists of a mapping between domains - what the designer wants to do and how he or she decides to do it. These domains can be in terms of function-behaviorstructure, FRs and DPs, and customer expectations and engineering characteristics, etc., [28, 69-71]. The interactions between elements in different design domains is represented in terms of matrices of design relationships. These matrices capture relationship either for elements within one domain, such as the design structure matrix (DSM) [71, 72] (see also, [73]), or between elements such as the axiomatic design matrix [28, 58], the multiple-domain matrix [74], and the house of quality (HoQ) in quality function deployment (QFD) [70].

Similar to engineering design, transdisciplinary research also involves mapping across multiple do- 


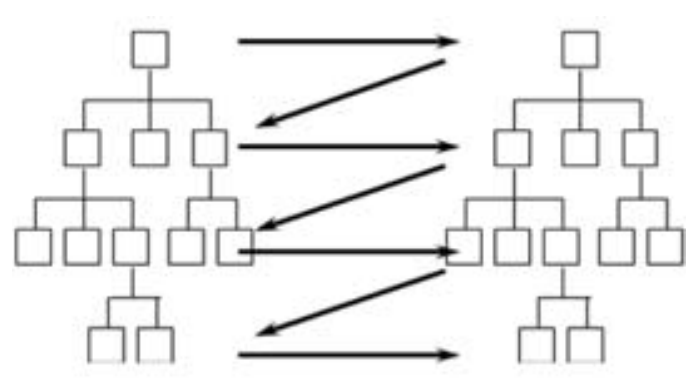

Figure 2: Hierarchies.

mains. In transdisciplinary research, goals are mapped to the products of various disciplines. These could consist of theoretical concepts, models of various phenomena, methods or tools that comprise the discipline and theories that connect the theoretical concepts, models, and observed phenomena using the methods or tools.

\section{Hierarchies}

The design process progresses from a system level to levels of more detail [68]. The decisions about the product or system are structured a hierarchical manner, as shown in Figure 2, and hierarchies exist for any design object in each of the domains, including functional, physical, and process. Hierarchies of requirements, solutions, and constraints range from systems levels to levels of increasing detail, from systems to subsystems to assemblies to parts to part features to material properties. Domains, mapping, and hierarchies provide a structure for information about the design decisions that have been made. The framing of design tasks in this way enables the identification of general patterns in design decisions $[28,40,50]$.

Many researchers in engineering design have used hierarchical structures to represent the flow of decision making in design, starting with Marples [57] and including function-means trees [40, 41, 54], axiomatic design [28, 58], and others.

Transdisciplinary research is inherently hierarchical. A large systemic problem is broken down into smaller pieces through mapping to various disciplinary pieces that are ultimately reintegrated into a new, holistic framework. Depending on the disciplines involved and the various elements that are adopted from each discipline, the smaller pieces are further decomposed until the researchers know what to do with them.

\subsubsection{Tools}

\section{Engineering Contradictions}

One criterion for choosing good engineering solutions is to choose solutions that minimize or eliminate system conflicts. System conflicts exist when attempts to improve some system attributes lead to the deterioration of other system attributes. A system conflict can be defined as (a) a useful action simultaneously causes a harmful effect, or (b) the introduction, or intensification, of a useful action or the elimination, or alleviation, of a harmful action causes an inadequacy or an unacceptable complication of one part or of the whole system. From a TRIZ standpoint, to make a good invention means to resolve a system conflict without compromise [36]. The existence of system conflicts has also been termed as a coupled design [28]. System conflicts can be at the level of engineering parameters such as a conflict between weight and strength, or power versus fuel consumption. They can also be manifest as physical contradictions such as the need to possess contradictory physical properties for different functional purposes, such a need to have both large and small size.

Both axiomatic design and TRIZ provide tools for problem formulation that help identify areas within a system or design that have system conflicts or are functionally coupled. Within TRIZ are several algorithms, methods, principles, and examples for creatively modifying systems to eliminate conflicts [35-37]. Axiomatic design, provides both qualitative and quantitative approaches for assessing coupling to provide an objective means for identifying good design [28]. Some of these tools and techniques would be helpful in transdisciplinary research to identify the conflicts among different disciplinary goals, models, and perspectives. Moreover, they should help participants from multiple disciplines to reduce their "psychological inertia" [34] and create 
a common language for their problem in a "solutionneural environment" [28].

\section{Modularity}

A design can be arranged into different "chunks" or modules (groups of physical components) [71, 75]. Modularity is the use of standard parts or interfaces to provide flexibility and variety in meeting customer needs. According to Websters dictionary, it is the use of standardized units or dimensions as a means for providing "flexibility or variety in use," [76]. Specifically, flexibility is defined as desired variety in inputs and outputs in performing functional requirements, and modularity is one strategy for providing this desired flexibility. The types of flexibility that are enabled by modular design include separate testing of functions, synthesis of products with custom functionality using new combinations of existing parts, and ease of product change. These benefits of modularity that are espoused by proponents do not correspond to a single uniform set of product characteristics: A wide range of possible benefits of modularity are given in [77] and [78], and Gershenson et al. give definitions and tools for modular design $[79,80]$.

Three types of modularity and associated metrics can be defined [68]: Resource modularity characterizes the ease of manufacturing or implementation; operational modularity characterizes the extent to which the users have options in the operation of the system; and interfacial modularity characterizes the amount of design effort embodied in an engineering change order (ECO). The first corresponds to the modularity of the design parameters, the second to the operation of the functional requirements, and the third to the modularity described within the design matrices that relate the functional requirements and design parameters.

In many situations modularity is a desirable characteristic from an engineering perspective. While the concept of separating problems into independent sub-tasks or problems is by definition antithetical to the transdisciplinary ethos, some of the concepts or measures of modularity may be useful to the transdisciplinary research community in either assessing the amount of integration needed for a particular problem or in more efficiently organizing research tasks and resource allocation. For example, Browning presents several uses of design structure matrices for structuring development activities, organizing development teams, or physically laying out systems
$[71,81],($ See also $[75])$

\subsection{Theory of Technology Evolution}

The above descriptions of engineering design processes can be combined with recent economics theories about technology development. Arthur states that the term technology as commonly used covers three distinct concepts. To clarify the differences, he looks at technology at three levels [82]:

1. The technologies embodied in a particular design

2. The families of technologies that comprise an engineering domain or discipline

3. A technium, which is technology as the whole "collection of devices and engineering practices available to a culture" at a time

Similarly transdisciplinary research efforts can be viewed in the context of the types of problems that are to be addressed:

1. The integration of knowledge for a particular research topic

2. Newly emerging bodies of knowledge that grow out of a community of researchers

3. The sum of knowledge available to society at one time

\subsection{Mechanism for Dynamic Knowledge Integration}

Specifically, the development of a new technology is "a [physical] phenomenon captured and put to use." This involves the combination of existing technologies. Arthur makes three claims about this evolution of technology [82]:

1. Novel technologies arise by combination of existing technologies.

2. "The stock of existing technologies must somehow provide the parts for combination. So the very cumulation of earlier technologies begets further cumulation....[T]herefore, existing technologies beget further technologies....These new technologies in time become possible componentsbuilding blocksfor the construction of further new technologies.... The overall collection of technologies bootstraps itself upward from 
the few to the many and from the simple to the complex. We can say that technology creates itself out of itself."

3. Technology builds out of both combination of existing technologies and the constant capturing and harnessing of additional natural phenomena.

Taken together these three claims are used to build a theory of technology that explains its evolution: "Modern technology is not just a collection of more or less independent means of production. Rather it is becoming an open language for the creation of structures and functions in the economy. Slowly, at a pace measured in decades, we are shifting from technologies that produced fixed outcomes to technologies whose main character is that they can be combined and configured endlessly for fresh purposes," [82] This explanatory mechanism can be applied to the transdisciplinary research process. Over time, efforts to address research topics expand from a focus on a particular system or situation under consideration to generating new bodies of knowledge that build upon each other and that continually integrate new discoveries, newly recognized physical phenomena, and new technologies. Transdisciplinary research seeks to integrate knowledge from existing disciplines in unique ways.

At the level of an individual research topic, it may be sufficient to bring together researchers representing multiple disciplines to investigate a common problem from diverse perspectives. If the results remain within the individual disciplinary frameworks, this would represent a multi-disciplinary approach. Kollman and Ertas describe an example of designing a wind turbine as a collection of individual subsystems: a structure designed by civil engineers, a gearbox designed by mechanical engineers, control systems and power transmissions designed by electrical engineers, etc., [14]. Many stakeholders may be represented in multidisciplinary efforts. If the system is free of system conflicts and coupling as described above, then modularization is possible. If so, tasks can be easily divided and work can be performed efficiently.

On the other hand, it is often desirable to consider the interfaces between the disciplines. In an example like the wind turbine design, changes that are made to gearbox may make structural design or power generation easier [14]. In this case, inter- disciplinary efforts are necessary. By working more closely together and explicitly considering the interfaces between modules and design activities, a more optimal solution can be obtained. As a result of this type of interaction, new bodies of knowledge and new bodies of technology may develop. New knowledge is being generated that can later serve as a building block or stepping stone for further efforts.

The final stage of knowledge integration requires broadening perspective even further. Such approaches to problem solving and technological system development consider areas far away from traditional discip disciplinary boundaries. In such cases, teams consider the social or environmental impacts of large-scale engineering or technical systems. Kollman and Ertas describe issues related to wide-spread use of wind power technology, including health effects from noise and vibration, visual impact on communities, effects on wildlife and bird migration, etc., [14]. These considerations would all normally be considered outside the bounds of an engineering problem. Ultimately some problems require creative solutions that draw upon the sum of knowledge available to society at one time - or may even be beyond the current scope of knowledge of society. In such cases researchers and practitioners need very open and creative approaches to search for analogies among far-flung disciplines, technologies, and scientific phenomena. New approaches to identify relevant analogies among disciplines and apply them to engineering systems are needed.

\subsubsection{Measures of Knowledge Integration}

One premise of transdisciplinary research is that innovative ideas embody the novel combination of solutions that already exist separately in other designs and in other disciplines. This empirical observation has been made in the management and economics literature of innovation research [83]. It has also been used as part of the definition of level of invention provided by TRIZ in combination with the concept of resolution of system conflicts [36]. Adams and Tate have presented an approach to tie these observations to the engineering design of innovative designs, thus characterizing innovative designs according to their level of interdisciplinary and transdisciplinary combination of knowledge [84-86].

The quantification of transdisciplinary knowledge integration has been applied to design information embodied in patent documents. The inter - and 
transdisciplinary knowledge integration measures that Adams developed were constructed through the use of natural language processing, latent semantic analysis, and information retrieval techniques to build a data set of disciplinary functional and physical terms. The definitions of the measurements take into account the distribution of functions and solutions that comprise one design idea.

When considering the distribution of these functions and solutions that are described as subjectaction object ( $\mathrm{SAO}$ ) terms over many disciplines (in a general sense this can be $\mathrm{n}$ disciplines), some of the terms will be found only in one discipline. Others will be found in two disciplines, three disciplines, etc. up to terms that appear across all $\mathrm{n}$ disciplines. There are two types of knowledge integration that can be recognized in these terms. The first is typified by SAO terms that are used across n (or some subset of $n$ ) disciplines; this represents transdisciplinary knowledge. The other type of knowledge integration is typified by a design idea that contains SAO terms that are present previously in one discipline (that is monodisciplinary functions and solutions) but that has synthesized a new integration of mono-disciplinary terms coming from what were previously $\mathrm{n}$ (or a subset of $\mathrm{n}$ ) distinct disciplines. This type of knowledge integration can be considered as interdisciplinary knowledge integration.

\subsection{Criteria for Assessing Transdisciplinary Research}

Scientific and other intellectual theories comprise fundamental knowledge areas in the form of perceptions and understandings of different entities, and the relations between fundamental concepts. The fundamental concepts are at a more abstract level than observations of real-world data. These perceptions and relations are combined by researchers or practitioners to produce specific consequences, for example, predictions of events to be observed [39, $68]$.

\subsubsection{Paradigms and Research Programs}

The establishment of a disciple or transdiscipline can be distinguished by its paradigm or research program and its research community. According to Kuhn a paradigm for research is a unifying view of a discipline ("the entire constellation of beliefs, values, techniques, and so on shared by the members of a given [research] community" [87]) that is brought about exemplars ("the concrete puzzle-solutions which [are] employed as models or examples...as a basis for the solution of the remaining puzzles of normal science" [87]). Thus, for example, Newton's Principia is a treatise which served as a unifying vision for the paradigm of Newtonian mechanics, and Dobzhansky's Genetics and the Origin of Species provides an exemplar for the paradigm of neo-Darwinian biology. A research program can be defined as "a sequence of theories representing the development of a central idea," [88]. Similarly, a research tradition consists of "(1) a set of beliefs about what sorts of entities and processes make up the domain of inquiry; and (2) a set of epistemic and methodological norms about how the domain is to be investigated, how theories are to be tested, how data are to be collected, and the like," [89].

Therefore, a paradigm or a research program consists of four interrelated items [39, 68]:

- aims: an articulation of the scope of the field in terms of both problems that have been solved (exemplars) and problems remaining to be solved (anomalies) which should be covered by the program-and are expected to be - but have not yet been

- methodology: guidelines for further developing the program - particularly in a manner consistent with the problem - solving approach that the program has been following

- theories: relationships between fundamental concepts of the field and application to specific problems

For transdisciplinary research, these items are not fixed. As Laudan indicates, paradigm change can be at many levels - ontology, methodology, or aims and change can occur for one or more of these items at a time [90]. In the case of transdisciplinary efforts, a new research program is established in response to a particular situation or a particular need. Once the area of interest is determined and a multidisciplinary research team is established, in a transdisciplinary effort, the team has the flexibility to determine the aims of the project: What is to be addressed? What issues cannot be solved using current disciplinary approaches? Then concepts, methods, and theories from participating disciplines can be examined for relevance; terminology can be refined, redefined, or 
created; and a new transdiscipline can be established for that particular problem or project. If the same disciplines repeatedly work together and the scope and depth of collaboration increase, over time a new body of knowledge representing a new research tradition can gel.

\subsubsection{Progressiveness}

Tate and Nordlund provide a generic research program for design that describes data gathering, theory development, use of theories, and theory validation. [39] The criteria for choosing a research program are related to - but not synonymous with - the existence of anomalies or counterexamples. Anomalies are defined as "recalcitrant instances, not [as] refutations" [91]. Specifically, anomalies are identified with the expectation that they will be "solved" by the research program. The issue is whether the process of solving these anomalies is done in a manner consistent with the programs heuristic-its programspecific set of problem-solving techniques [88]. As an example, for Newtonian mechanics, its heuristic consists of its mathematics: differential calculus, differential and integral equations, etc. [88] Given that all theories have anomalies (according to Popper's definition, they would be considered to be falsified), the quality may be judged according to the following criteria. A progressive research program meets three conditions [88]:

- Theoretically progressive condition: It must make new and interesting predictions, that is, undreamed of [88] by other programs. And these predictions are particularly good if they are counterexamples to rival research programs [91].

- Empirically progressive condition: Some of these predictions must be corroborated by the experimental evidence.

- Heuristically progressive condition: Furthermore, when anomalies are identified, the progressive program must be accommodating and explaining these anomalies in a manner consistent with the spirit of its heuristicas opposed to in an ad hoc manner.

Transdisciplinary research efforts can be compared against these criteria. By definition they have a basis for comparison in their respective disciplines. So the criteria concern the relative merits of the transdisciplinary results compared with the disciplinary alternatives. Are the transdisciplinary theories able to explain and predict new phenomena that the old theories could not address? Do the results match the predictions? Is the research program making progress in way that is consistent with its heuristic? If so, the particular transdisciplinary approach is a success; if not, an alternative should be found. Degenerating programs, by definition, do not meet the above criteria.

\section{Examples of Transdisciplinary Research in Engineering}

Several recent research topics in engineering highlight cross-disciplinary knowledge transfer and transdisciplinary research approaches. These include sustainable design, biomimetic design, and engineering innovation.

\subsection{Sustainable Design}

Sustainable design can be defined as incorporating larger environmental, resource, and social issues into decisions of the conceptualization, design, manufacture, operation, and end-of-life of products and systems. These larger issues include, for example, environmental concerns, energy independence, and social impact. The sustainable design concepts and approaches should be driven by social and industrial needs while addressing forward-looking issues including the design and development of innovative products and service systems that use dramatically less energy, the provision of energy using "green" technologies, minimizing impact on the environment and biosphere, economic viability, and promotion of social well being for current and future generations. Efforts to teach sustainable design need to instill an appreciation for the innovation processes by which the sustainable designs can be adopted [92].

\subsection{Biomimetic Design}

Biomimetic systems design is the use of biological models to solve analogous engineering problems. Biological systems can provide stimulation for many various design objectives, including adaptability to changing environments, optimization, sustainability, repair, risk analysis and remanufacture. Systematic 
methods and processes are proposed for engineers to access biological knowledge, identify analogical biological phenomena, comprehend material in the biological disciplines, choose one or more analogies, and apply analogical reasoning to create new knowledge.

Transdisciplinary research activities can progress through several levels of increasing scope of knowledge integration and collaboration. Biomimetic design is an example: it can be conducted at the level of an individual project - one engineering system or problem to be solved, such as mimicking the texture of shark skin or dynamic cross-section changes in wing profile - or it can be considered at the level of a growing body of knowledge that spans biology, mechanisms, materials, and controls. Most of the efforts in generic approaches to biomimetic design have been in the area of electro-mechanical systems and within the mechanical engineering community [93-96]. These efforts have not yet been integrated with computer science or software engineering to form the third level of transdisciplinary knowledge integration. There have been some efforts at mimicking for example, the human immune system for software intrusion detection, but these efforts have not joined with the efforts from mechanical disciplines.

\subsection{Engineering Innovation}

One research area in which the need for transdisciplinary approaches has been recognized is that of innovation. Recent publications and workshops have articulated the need for tighter integration between engineering design research and the study of innovation [97-99], the process by which technological changes are introduced and spread. [I]nnovation in its broadest sense ... refer[s] to the entire process by which technological change is deployed in commercial products, [31]. Innovation is a broader activity than invention: "A technology may be invented, but it will not be an innovation until it is widely applied" [2].

No single discipline deals with all aspects of innovation, thus there is a tendency towards crossdisciplinary research in the field. To get a comprehensive view, the insights from several disciplines must be combined [30]. Economics treats the innovation process as a "black box" and deals primarily with the allocation of resources to innovation and its economic effects. For example, economics studies the economic impact of technological change and how different nations or regions support or hinder innovative activity. Cognitive science and cognitive psychology investigate the creativity used and the learning that occurs in the process. Organizational settings are studied within sociology, organizational science, management, business, and social psychology. Economic geographers tie innovative learning processes to specific contexts or locales, which can change over time as explained in economic history. Finally history of technology investigates the links between the specific technology and the organization, economic, and social effects [30, 31].

\section{Challenges and Opportunities}

Sperber describes the challenges faced in interdisciplinary work and recognizes that current efforts do not go far enough in promoting understanding and cooperation between disciplines. While "grant proposals...have built in interdisciplinary rhetoric and describe future collaboration among people from different disciplines,...this is mostly done in order to meet the criteria for the grant. The actual scientific content generally consists in the juxtaposition of monodisciplinary projects with some effort to articulate their presentation." Sperber believes that the easiest way to have interdisciplinary work received is not to present it as such, but "to produce different versions of it for each of the disciplines concerned," [13]. Much of the difficulty of interdisciplinarity is due to the fact that attention, recognition, and authority are channeled by disciplinary institutions, yet researchers should recognize that "disciplines are artificial 'holding patterns' of inquiry whose metaphysical significance should not be overestimated." Researchers should not have a "providential view of the history of science [that] science is normally as it ought to be." This view "refuses to consider that science (or a particular science), had it pursued a different course of inquiry earlier in its history, would have ended up in a better epistemic position than it is in today. It simply take[s] for granted that [there could be no better outcome than that resulting from the choice] to dump Aristotle for Newton, Newton for Einstein, etc.and at roughly the times and for the reasons they were dumped," [100].

The prospect of transdisciplinary research is exciting. The growth of globalization, cyberinfrastructure, and other enabling technologies should facili- 
tate broader participation in research and innovation activities. New networks of researchers can be created in a short time, and other non-traditional participants can become involved in solving the worlds problems. Whenever invention or innovation occurs, someone has recognized a need and acted upon it. The inventor or innovator identified shortcoming with existing designs, systems, technologies, theories, etc. and acted upon that insight [101]. Imagine the what-if scenario in which individuals around the world recognize needs in their own communities and have access to the engineering, science - even transdisciplinary research - and build new knowledge to realize their visions for solutions.

\section{Conclusions}

This paper has presented challenges faced due to rapidly accelerating technological development and the need for a transdisciplinary approach to engineering systems. The focus of the paper was on drawing an analogy between transdisciplinary research and theories of engineering design and technological system development. The analogies were used to propose a mechanism for dynamic knowledge integration using transdisciplinary approaches based on a three-level progression of the scope of transdisciplinary research activities. Concepts and tools from engineering design and innovation were used to explain challenges and opportunities for the future of transdisciplinary research, and preliminary measures for transdisciplinary and interdisciplinary knowledge integration were discussed. Validation of transdisciplinary research was presented in light of approaches to philosophy of science and the sociology of intellectual discourse. Finally examples of transdisciplinary research areas that combine engineering design with other fields such as sustainability, biology, and management of technology were given.

\section{References}

[1] National Academy of Engineering, 2007. Greatest Engineering Achievements of the 20th Century.'

[2] Bainbridge W.S., Roco M.C. (eds.), 2006, Managing Nano-Bio-Info-Cogno Innovations. Dordrecht, The Netherlands: Springer. ISBN 978-1-4020-41068/978-1-4020-4107-5.

[3] Landler M., Clark N., Dougherty C., 2006. Airbus Moves to Rewire Its Management First.
The New York Times, New York, NY, Oct. 13. http://query.nytimes.com/gst/fullpage.html?res =9C00E1DE1130F930A25753C1A9609C8B63\& $\mathrm{sec}=\&$ spon $=\&$ pagewanted $=$ all.

[4] Rosenberg S., 2007. At Microsoft, a Sad Software Lesson. The Washington Post, Washington, D.C., p. A17, Jan. 30. http://www.washingtonpost.com/wpdyn/content/article/2007/01/29/AR2007012901 450.html.

[5] Eggen D., Witte G., 2006. The FBI's Upgrade That Wasnt: $\$ 170$ Million Bought an Unusable Computer System. Washington Post, Washington, DC, p. A01, Aug. 18.

[6] National Academy of Engineering, 2004. The Engineer of 2020, Washington, DC: The National Academies Press.

[7] National Academy of Engineering, 200. Educating the Engineer of 2020, Washington, DC: The National Academies Press.

[8] Hastings D., 2005. ESD Strategic Plan. Massachusetts Institute of Technology, Engineering Systems Division, Cambridge, MA.

[9] Grinter, L.E., 1955. Summary of the Report on Evaluation of Engineering Education. Journal of Engineering Education, pp. 25-60.

[10] Dym C.L., Agogino A.M., Eris O., Frey D.D., Leifer L.J., 2005. Engineering Design Thinking, Teaching, and Learning. Journal of Engineering Education, 94(1), pp. 103-120.

[11] Fauvel O., Winkelman P., Caswell D., 2002. Engineering, Science, and Design Learning. NSF Design, Service and Manufacturing Grantees \& Research Conference, San Juan, PR.

[12] Simon H.A., 2001. The Role of Software Engineering in Systems for Design And Process Control. Journal of Integrated Design and Process Science, 5(3), pp. $5-11$.

[13] Sperber D., 2003. Why Rethink Interdisciplinarity? Rethinking Interdisciplinarity. http://www.interdisciplines.org/interdisciplinarity /papers/1, accessed: August, 22, 2010.

[14] Kollman T.E., Ertas A., 2010. Defining Transdisciplinarity. The ATLAS TransdisciplinaryTransnational- Transcultural Bi-Annual Meeting, TheATLAS Publications, Georgetown, TX, pp. $22-38$. 
[15] Nicolescu B., 2010. Methodology of Transdisciplinarity - Levels of Reality, Logic of the Included Middle and Complexity. The ATLAS TransdisciplinaryTransnational-Transcultural Bi-Annual Meeting, The- ATLAS Publications, Georgetown, TX, pp. $1-14$.

[16] Pohl C., 2010. From Transdisciplinarity to Transdisciplinary Research. The ATLAS TransdisciplinaryTransnational-Transcultural Bi-Annual Meeting, TheATLAS Publications, Georgetown, TX, pp. 1-14.

[17] Oxford English Dictionary. Transdisciplinary. http://dictionary.oed.com/cgi/entry/50256143?single $=1 \&$ query-type $=$ word\&queryword =transdisciplinary \&first $=1 \& \max$-to-show $=10$, accessed: Nov. 14 , 2005 .

[18] Ertas A., Maxwell T., Rainey V.P., Tanik M.M., 2003. Transformation of Higher Education: The Transdisciplinary Approach in Engineering. IEEE Transactions on Education, 46(2), pp. 289-295.

[19] Ertas A., 2010. Understanding of Transdiscipline and Transdisciplinary Process. Transdisciplinary Journal of Engineering \& Science, 1(1), pp. 17-25.

[20] Ertas A., 2000. The Academy of Transdisciplinary Education and Research (ACTER). Journal of Integrated Design and Process Science, 4(4), pp. 13-19.

[21] Ertas A., 2000. Transdisciplinary Engineering Education and Research Model. Journal of Integrated Design and Process Science, 4(4), pp. 1-11.

[22] Petroski H., 2010. The Essential Engineer: Why Science Alone Will Not Solve Our Global Problems: Knopf.

[23] Tate D., Chandler J., Fontenot A.D., Talkmitt S., 2010. Matching Pedagogical Intent with Engineering Design Process Models for Pre-College Education. Artificial Intelligence for Engineering Design, Analysis and Manufacturing, 24, pp. 379-395.

[24] National Academy of Engineering, 2008. Changing the Conversation: Messages for Improving the Public Understanding of Engineering. Washington, D.C.: National Academies Press.

[25] Sohlenius G., 1990. Presidential Address. Annals of the CIRP, $39 / 2$.

[26] Simon H.A., 1996. The Sciences of the Artificial. Third Edition, Cambridge, MA: MIT Press.

[27] Kline R.R., 2000. The Paradox of 'Engineering Science' A Cold War Debate about Education in the U.S. IEEE Technology and Society Magazine, May, pp. 19-25.
[28] Suh N.P., 1990. The Principles of Design. New York: Oxford University Press.

[29] Suh N.P., 2005. Complexity: Theory and Applications. New York: Oxford University Press.

[30] Fagerberg J., Mowery D.C., Nelson R.R. (eds.), 2005. The Oxford Handbook of Innovation. Oxford, UK: Oxford University Press. ISBN 0-19-926455-4.

[31] Chesbrough H., Vanhaverbeke W., West J. (eds.), 2000. Open Innovation: Researching a New Paradigm. Oxford, UK: Oxford University Press. ISBN 978-0-19-929072-7.

[32] von Hippel E., 2005. Democratizing Innovation. Cambridge, MA: MIT Press.

[33] Li Z., Tate D., 2010. Mass Innovation Approaches for Systematic Innovation: Automatic Function Interpretation applied to Sustainable Design. First International Conference on Systematic Innovation, Hsinchu, Taiwan.

[34] Altshuller G.S., 1984. Creativity as an Exact Science. (translated by A. Williams), New York: Gordon and Breach.

[35] Clausing D., Fey V., 2004. Effective Innovation: Developing Winning Technologies. New York, NY: ASME Press.

[36] Fey V., Rivin E., 2005. Innovation on Demand. Cambridge, UK: Cambridge University Press.

[37] Savransky S.D., 2000. Engineering of Creativity. Boca Raton, FL: CRC Press.

[38] Tate D., Nordlund M., 1998. A Design Process Roadmap as a General Tool for Structuring and Supporting Design Activities. SDPS-Journal of Integrated Design and Process Science, 2(3), pp. 11-19.

[39] Tate D., Nordlund M., 2001. Research Methods for Design Theory. ASME DETC01, DETC2001/DTM21694, Pittsburgh, PA.

[40] Hubka V., Eder W.E., 1992. Engineering Design. Zrich, Switzerland: Heurista.

[41] Hubka V., Eder W.E., 1996. Design Science. London: Springer.

[42] Pahl G., Beitz W., Feldhusen J., Grote K.-H., 2007. Engineering Design. (edited by K. Wallace and L. Blessing), Third edition, London: Springer.

[43] Fulcher A.J., Hills P., 1998. A Taxonomy of Design Research Topics by Multivariate Agglomerative Clustering. Journal of Engineering Design, 9(4), pp. 343-354. 
[44] Ross D.T., 1985. Applications and Extensions of SADT. Computer, 18(4), pp. 25-34.

[45] Chakrabarti A. (ed.), 2002. Engineering Design Synthesis. London, UK: Springer. ISBN 1-85233-492-4.

[46] Antonsson E.K., Cagan J. (eds.), 2001. Formal Engineering Design Synthesis. Cambridge, UK: Cambridge University Press. ISBN 0-521-79247-9.

[47] Hirtz J., Stone R.B., McAdams D.A., Szykman S., Wood K.L., 2002. A functional basis for engineering design: Reconciling and evolving previous efforts. Research in Engineering Design, 13(2), pp. 65-82.

[48] Stone R.B., Wood K.L., 2000. Development of a Functional Basis for Design. Journal of Mechanical Design, 122(4), pp. 359-370.

[49] Stone R.B., Hirtz J., McAdams D.A., Szykman S., Wood K.L., 2002. A Functional Basis for Engineering Design: Reconciling and Evolving Previous Efforts. Research in Engineering Design, 13, pp. 65-82.

[50] Pahl G., Beitz W., 1996. Engineering Design. (edited by K. Wallace), Second edition, London: Springer.

[51] Marca D.A., McGowan C.L., 1993. IDEF0/SADT, San Diego, CA: Eclectic Solutions.

[52] Ross D.T., 1977. Structured Analysis (SA): A Language for Communicating Ideas. IEEE Transactions on Software Engineering, SE-3, 1, pp. 16-34.

[53] Ross D.T., Schoman K.E., Jr., 1977. Structured Analysis for Requirements Definition. IEEE Transactions on Software Engineering, SE-3(1), pp. 6-15.

[54] Andreasen M.M., 1991. The Theory of Domains. Workshop on Understanding Function and Function to Form Evolution, Cambridge, UK.

[55] Andreasen M.M., Hansen C.T., Mortensen N.H., 1995. On Structure and Structuring. in 6. Symposium on Fertigungsgerechtes Konstruieren, Erlangen/Egloffstein, Germany.

[56] Andreasen M.M., Hein L., 1987. Integrated Product Developmen. New York: Springer-Verlag.

[57] Marples D.L., 1961. The Decisions of Engineering Design. IRE (Institute of Radio Engineers) Transactions on Engineering Management, EM-8(2), pp. $55-71$.

[58] Suh N.P., 2001. Axiomatic Design: Advances and Applications. New York: Oxford University Press.

[59] Johannesson H., 2004. Function-Means Based Conflict Analysis In Conceptual Design of System Products. in 7th Workshop on Product Structuringproduct platform development, Goteborg: Chalmers University of Technology.
[60] Qian L., Gero J.S., 1996. Function-behaviorstructure Paths and Their Role in Analogy-based Design. Artificial Intelligence for Engineering Design, 10, pp. 289-312.

[61] Welch R.V., Dixon J.R., 1992. Representing Function, Behavior and Structure during Conceptual Design. Design Theory and Methodology (DTM 92), ASME, DE-42, Scottsdale, AZ, pp. 11-18.

[62] Galle P., 2009. The ontology of Geros FBS model of designing. Design Studies, doi:10.1016/j. destud.2009.02.002.

[63] Dorst K., Vermaas P.E., 2005. John Geros FunctionBehaviour-Structure model of designing: a critical analysis. Research in Engineering Design, 16, pp. 1726.

[64] OMG Systems Modeling Language (OMG SysML), 2008, Version 1.1, Nov.

[65] Hause M., Thom F., Moore A., 2005. Inside SysML. Computing \& Control Engineering Journal, 16, 4, pp. 10-15.

[66] Erden, M. S., Komoto H., van Beek T. J., D'Amelio V., Echavarria E. and Tomiyama T., 2008. A review of function modeling: Approaches and applications. Artificial Intelligence for Engineering Design, Analysis and Manufacturing, 22, pp. 147-169.

[67] van Eck D., McAdams D.A., Vermaas P.E., 2007. Functional Decomposition in Engineering: A Survey. in IDETC/CIE 2007, Las Vegas, NV: ASME, pp. DETC2007-34232.

[68] Tate D., 1999. A Roadmap for Decomposition: Activities, Theories, and Tools for System Design. Ph.D. Thesis, Department of Mechanical Engineering, MIT, Cambridge, MA.

[69] Umeda Y., Ishii M., Yoshioka M., Shimomura Y., Tomiyama T., 1996. Supporting Conceptual Design based on the Function-behavior-state Modeler. Artificial Intelligence for Engineering Design, 10, pp. 275-288.

[70] Clausing D., 1994. Total Quality Developmen. New York: ASME Press.

[71] Browning T.R., 2001. Applying the Design Structure Matrix to System Decomposition and Integration Problems: A Review and New Directions. IEEE Transactions on Engineering Management, 48(3), pp. 292-306.

[72] Steward D.V., 1981. The Design Structure System: A Method for Managing the Design of Complex Systems. IEEE Transactions on Engineering Management, EM-28(3), pp. 71-74. 
[73] Warfield J.N., 1994. A Science of Generic Design, Second Edition. Ames: Iowa State University Press.

[74] Lindemann U., Maurer M., Braun T., 2009. Structural Complexity Management: An Approach for the Field of Product Design. Berlin: Springer-Verlag

[75] Pimmler T.U., Eppinger S.D., 1994. Integration Analysis of Product Decompositions. ASME, DE68 , pp. 343-351.

[76] Merriam-Websters, 1996. Merriam-Websters Collegiate Dictionary. Springfield, MA: MerriamWebster http://www.eb.com:180/search/search.htcl, accessed: September 12, 2010.

[77] Erixon G., 1998. Modular Function DeploymentA Method for Product Modularisation. Doctoral Thesis, Department of Manufacturing Systems, The Royal Institute of Technology (KTH), Stockholm, Sweden.

[78] Ulrich K., Tung K., 1991. Fundamentals of Product Modularity. Issues in Design Manufacture/Integration, ASME, DE-39, Atlanta, GA, pp. 73-80.

[79] Gershenson J.K., Prasad G.J., Zhang Y., 2004. Product Modularity: Measures and Design Methods. Journal of Engineering Design, 15(1), PP. 33-51.

[80] Gershenson J.K., Prasad G.J., Zhang Y., 2003. Product Modularity: Definitions and Benefits. Journal of Engineering Design, 14(3), PP. 295-313.

[81] Browning T.R., 2001. Process Integration using the Design Structure Matrix. Systems Engineering, 5(3), pp. 180-193.

[82] Arthur W.B., 2009. The Nature of Technology, New York, NY: Free Press.

[83] Utterback J.M., 1994. Mastering the Dynamics of Innovation, Boston, MA: Harvard Business School Press.

[84] Adams C., 2009. Developing Transdisciplinary Engineering Metrics using Data Mining Techniques. Ph.D. Dissertation, Mechanical Engineering Department, Texas Tech University, Lubbock, TX.

[85] Adams C., Tate D., 2009. Computer-Aided TRIZ Ideality and Level of Invention Estimation Using Natural Language Processing and Machine Learning. in Growth and Development of Computer-Aided Innovation: Third International Federation of Information Processing (IFIP) WG 5.4 Working Conference, Harbin, China, CAI Aug. 20-21, 2009 Proceedings, R. Tan, G. Cao and N. Len, (eds.), Berlin: Springer, pp. 27-37. ISBN 978-3-642-03345-2.
[86] Adams C., Tate D., 2010. Transdisciplinary Tools for Innovative Design Exploration. The ATLAS Transdisciplinary- Transnational-Transcultural BiAnnual Meeting, Georgetown, TX, PP. 39-47.

[87] Kuhn T.S., 1970. The Structure of Scientific Revolutions. Chicago, IL: University of Chicago Press.

[88] Larvor B., 1998. Lakatos: An Introduction, London: Routledge.

[89] Laudan L., 1996. Beyond Positivism and Realism, Boulder, CO: Westview Press.

[90] Laudan L., 1998. Dissecting the Holistic Picture of Scientific Change. in Philosophy of Science: The Central Issues, M. Curd and J.A. Cover, (eds.), New York, NY: W.W. Norton and Company, pp. 139-169. ISBN 0-393-97175-9.

[91] Lakatos I., 1978. Philosophical Papers Volume 1: The Methodology of Scientific Research Programmes, (edited by J. Worrall and G. Currie), Cambridge, UK: Cambridge University Press.

[92] Tate D., Maxwell T., Ertas A., Zhang H.-C., Flueckiger U.P., Lawson W., Fontenot A.D., Chandler J., 2010. Transdisciplinary Approaches for Teaching and Assessing Sustainable Design, International Journal of Engineering Education, 26(2), pp. 1-12.

[93] Chiu I., Shu L.H., 2005. Natural Language Analysis for Biomimetic Design. ASME DETC04, DETC200457250, Salt Lake City, UT.

[94] Shu L.H., Lenau T.A., Hansen H.N., Alting L., 2003. Biomimetics Applied to Centering in Microassembly. Annals of the CIRP, 52(1), pp. 101-104.

[95] Vakili V., Shu L.H., 2001. Towards Biomimetic Concept Generation. in ASME 2001 Design Engineering Technical Conferences, DETC2001/DTM-21715, Pittsburgh, PA: ASME.

[96] Tinsley A., Midha P.A., Nagel R.L., McAdams D.A., Stone R.B., Shu L.H., 2007. Exploring The Use of Functional Models as a Foundation for Biomimetic Conceptual Design. ASME 2007 International Design Engineering Technical Conferences, ASME, Las Vegas, NV, pp. DETC2007-35604.

[97] Shah J.J., Finger S., Lu S., Leifer L., Cruz-Neira C., Wright P., Cagan J., Vandenbrande J., 2005. ED2030:Strategic Plan for Engineering Design (NSF GRANT \# DMI-0411591). 2005 NSF Design, Service and Manufacturing Grantees and Research Conference, NSF, Scottsdale, AZ.

[98] McCarthy J.M., 2005. Editorial: Engineering Design in 2030: Human Centered Design. Journal of Machine Design, 127, p. 357. 
[99] McCarthy J.M., 2005. Editorial. Journal of Machine Design, 127, p. 169.

[100] Fuller S., 2003. Interdisciplinarity: The Loss of Heroic Vision in the Marketplace of Ideas. Rethinking Interdisciplinarity. http://www.interdisciplines. org/interdisciplinarity/papers/3., accessed: September 2, 2010.

[101] Lienhard J.H., 2006. How Invention Begins, New York, NY: Oxford University Press.

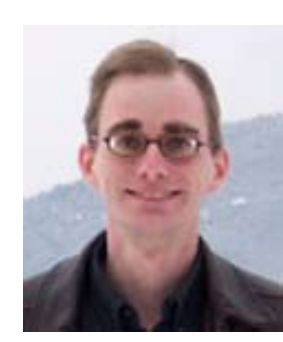

Dr. Derrick Tate is an Assistant Professor in the Mechanical Engineering Department at Texas Tech University. He aims to impact society through bringing design thinking to areas of strategic importance: developing sustainable approaches for building systems, transportation, and manufacturing; facilitating mass innovation; and enabling innovation in enterprises. His current projects working with West Texas entrepreneurs on the development of innovative and sustainable designs and a USTanzania Workshop: Advancing the Structural Use of Earth-based Bricks, funded by NSF. He received a B.S. in Mechanical Engineering degree from Rice University. His S.M and Ph.D. degrees in Mechanical Engineering are from MIT in the areas of manufacturing and design, respectively..

Copyright (C) 2010 by the author. This is an open access article distributed under the Creative Commons Attribution License (https://creativecommons.org/licenses/ by/4.0/), which permits unrestricted use, distribution, and reproduction in any medium, provided the original work is properly cited. 